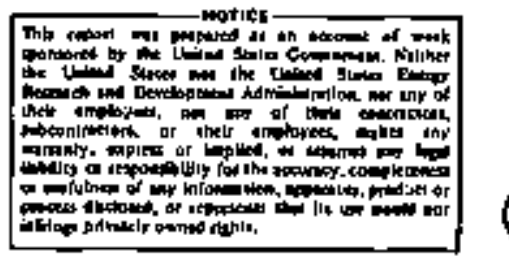

PATH INTEGRAL QUANTIZATION OF SOLITONS*

$$
\text { A. Jewicki }
$$

Irattlute for Advanced Study. Drincaton. New Jersey 08540

\section{ABSTRAG T}

A reviaw of sorne recent work on the collectlute coordinate approach to perturbation expangion about aliton solutions lo preatnted. Condittent formulation of the method in Cramework of the Feymmen path lntegral quantization groeedure in detctibed. Ad an illugtrative applicstion we digcune in detaif a perturbation expansion foz ecattering of eolitons,

\section{MASTER}

A ta lk given at the Coral Gablea Conlerence, January 16-21, 1971. 1 Regeareh aponsored by the Energy Recescoh and Dovelopment Adminiștration Grant Ho. E $\{11-1\}-2220$.
After the reletrance of gla $\mathrm{B}$ sical soliton solutions to the quentum theory has beeth ettablished at the seni-clasaleal level, the main problem remaining was to develop a syotematic pesturbation expansion about thls solutions, The straightforward way of doing this which consists of shifting the field by the clasticil a olution rune into serione diffienltikr. Namely, by the ohlit various armmetries flike transfational inyzriencel get broken and congequently zefo freguedcy modes appeap leading to an infrared problem. The most elfective way of eliminating this difficulty it given by the eallective caordinate method in which a proper treatment of symmetry degreet of freedom is actieved, In this approuch it is then Easy to develop a congitent set al Fepngan rulea and formulate a syctematic perturbation expanajon. ${ }^{3}$

In what Jollowg we will revitw a ornt further work on collective condinates ard their application to goliton goantization, most of which wa done during the last yea $r$ in collaboration with J. I. Gervais, First, in sec. I we give o britf summary of the canonieal collective coordirate method. Then in sec. If a nontrivial spplication is prestented on the tx. smple of colition ocattering. Finslly in sec. III we deteribe an alterative, noncanotical treatrient of zero Irequericy modes.

I. THE CANONICAL COLLECTTVE COORDINATE ME THOD In the fritial wark dealing with the one sojit on iactior parturba. tion axpansiog $2,4,5$ the center of mas position was trested as a collective 


\section{DISCLAIMER}

This report was prepared as an account of work sponsored by an agency of the United States Government. Neither the United States Government nor any agency Thereot, nor any of their employees, makes any warranty, express or implied, or assumes any legal liability or responsibility for the accuracy, completeness, or usefulness of any information, apparatus, product, or process disclosed, or represents that its use would not infringe privately owned rights. Reference herein to any specific commercial product, process, or service by trade name, trademark, manufacturer, or otherwise does not necessarily constitute or imply its endorsement, recommendation, or favoring by the United States Government or any agency thereof. The views and opinions of authors expressed herein do not necessarlly state or reflect those of the United States Government or any agency thereof. 


\section{DISCLAIMER}

Portions of this document may be illegible in electronic image products. Images are produced from the best available original document. 
par lable gince it wa nucessary to pregerve tratslational invariance when abrafing by a apace depardent clatsical solutico. To treat moro complicated soliton rolution, we have (ormulated is collaboration with J. L. Gerval, and B. Sakifa * general enethod of coflective coordirate in ref. (6). The bate ides conaista w promoting the symutery porameters $X_{\alpha}$, which appeat in certain classical bolution $\phi_{e q}\left\{x_{1}\right.$ t: $X_{\alpha} \mid$ to dyamical varlables (collectlve coordibatea). Thelr conjugate vart-

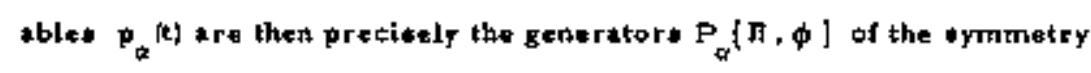
groop. This new at of caronical variables fo introduced into the path integral axpretsion for transition amplitude

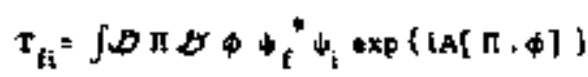

by uoling the ident lties

$$
\begin{aligned}
& \int \prod_{a} \delta p_{a} \frac{I I}{t} \&\left(p_{\alpha}(t)-P_{a}[I, \phi \mid)=1\right.
\end{aligned}
$$

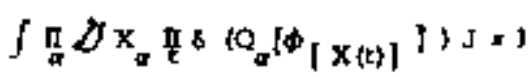

$$
\begin{aligned}
& J \times \operatorname{det}\left\|\frac{\partial Q_{o}}{\partial x_{F}}\right\| \text {. }
\end{aligned}
$$

Here $\phi_{[} x_{]}$denoted the traneform of $\phi$ and the ${ }_{\alpha}$ ' 3 repreaent arbitrary ofmmetry fixing conditlons. The collectlvt coordinates can be trangferred into the action by purforming a canonical traneformation

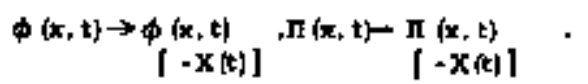

Furthermore If the litital and final otatee represent tigeostates of the conberved quaniltiet $P_{\alpha}$ it lo possible to in:egrate out the collective varlables and obtain

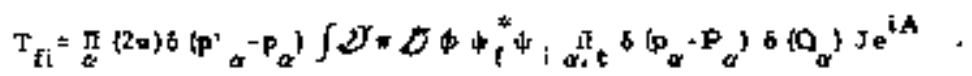

This result is formal gince in deriving it ot madt a canonical tranacormation by formally changing variables in the path integral.

In general it ts not known how to parform canonical trassformations in quankum theory. We have mada in ref, (t) an investigation of point trensformation, in the path integtal gince they are the onts most ofter used in applications of the collective coordinate method. Let ue condider a gentefil *yetem with nedegretes of fretdorn

$$
\left.L(q, q)=\frac{2}{2} \sum_{2} q_{*}{ }^{2}-v_{q}\right\}_{J}
$$

in preopnce af an external source J. The generating funetiosal io then given by

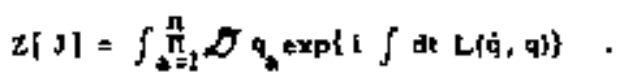

Performing a point transformation $q_{B}=F^{*}(O)$ we obtaln formally

$$
\int \prod_{i}^{n} D O_{i} g(Q)^{\frac{L}{3}} \exp \left(i f d t L\left(F, \dot{Q}_{i}, F(Q)\right)\right.
$$

there

$$
\begin{aligned}
& F_{, i}^{2}=\frac{\partial}{\partial Q_{i}} F^{2}(Q) \\
& g_{1 j}=\sum_{=1}^{n_{j}} F_{, j} F_{, j} \\
& \mathrm{~B}=\operatorname{det} \mathbf{E}_{\mathrm{hj}} \text {. }
\end{aligned}
$$

Hotevar, by maklag use of the diagram technique one can show that thi expreation differe from the orlginal generating functiond (1. 5). This means that a formal cbange of integration varisbles does not represtint a correct ateg in the poth integral. 
To derive the correct angwer wa use a more precive form tor the path lintegra!

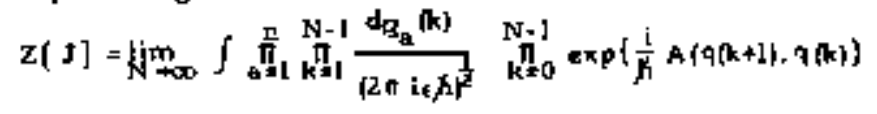

obtained by devidifg the llme ithterval into $N$ equal intervals $t=T / N$ and denoting $t_{k}=k, q(k) \equiv q\{k+1\}$. Then atter the chang* of variables $a_{a}\{k\}$ × $F^{2}(Q(k))$, the new short-time ection becomes

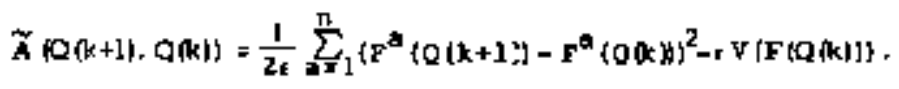

Now it is erueial to abeerve that it if not cotrect to approximate this

\section{apreadion by using}

$$
F^{A}(Q(k+1))-F^{A}(Q[k))=F_{, i}^{*} \Delta Q(k)
$$

since in the path integral $\Delta Q=O\left(f^{\frac{1}{2}}\right.$ ) and not $O(4)$. Deciding to expand about the mifpoint $\bar{Q}(k)=\frac{1}{a}[Q(k+1)+2(k))$ the corret approximation for the short-time action resda

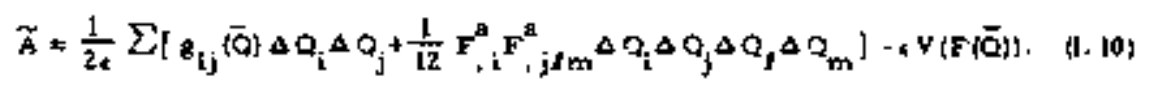
similerly for the measure we bbtain

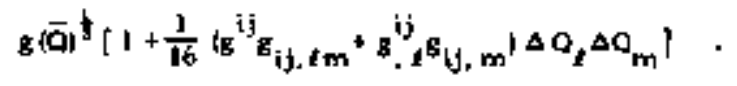

Next it is posable to subutitute the additional terms appening in A. 10) and (A. Il) by an equivalent potential term. The form of this sdditional potential is

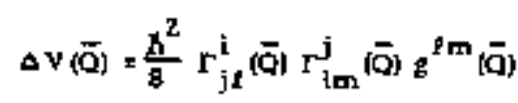

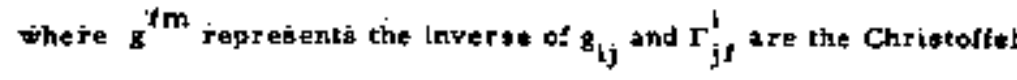
symbole.
To gumralize, we have found that * eareful treatment of point transformations in the path integral leads to

(a) An additional get of vertices coming from $\Delta \vee(Q)$.

(b) Specificatior. cf the ciherwise ambiguous contractions at the antic point 21 implied by the midpoint path integral.

Using this general result it is then simple to derive the correst Feypmsn fulten in the path iotegral collective coordinate method. We can alse mention that it i* not difficult lo demonateate the equivalence of this method with the parallel operator approach. ${ }^{8}$ However there are certain ad. vantages to the path integral apprach, since flest of all it leade directly to the Foymon rules and furthermore it apposto to be more powerful in digcusging more complicated procesece lika for example acattering of solitons.

\section{AN ILLUSTRATIVE APPLLCATION: PERTURBATION EXPANSTON FOR SOLITON SCATTERINC}

By now the re is an extensive literature on applications of the collective coordinate method to develop perturbation expansione in the on: soliton aector for various field theories. In contrant. the multi-coliton sector appears to be mech lets studled aince it is compiderably morg difficult to treat. So instezd of going over the variona one aoliton eector examples we choose to diseus in thit acetion the problem of soliton scattering. "It is here that the full power of the path integral approach becomes evidęnt. 
We contider the itit-Gordon model

$$
\begin{aligned}
& L(\phi)=\frac{1}{1}(\phi)^{2}-V(\omega) \\
& v(\phi)=\frac{1}{Y} n-\cos \left(V_{Y} \phi\right)
\end{aligned}
$$

since for this aded exact multi-soliton solutlons are known. The atathe solkton and antioliton solutlona read

$$
\begin{aligned}
& \phi_{B}(x)=\frac{4}{\sqrt{y}} \operatorname{tg}^{-1} e^{x} \\
& \phi_{A}(x)=\frac{4}{\sqrt{y}} t^{-1} e^{-x}
\end{aligned}
$$

and their mont is $M_{0}=8 / Y$. Our trestrant of the splitan-antioditon

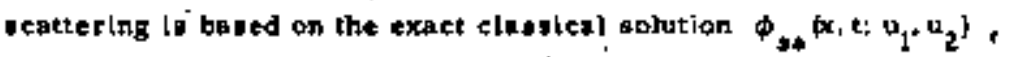
whlch dectsibes the trandition of coliton and the antionliton through each other. It had the following asymptotic behavior

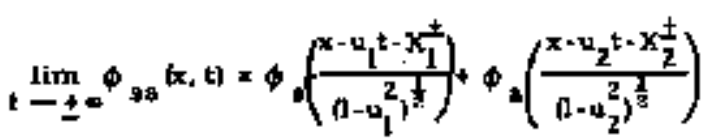

ot that after the colliotion only the pouitions become changed

$$
\begin{aligned}
& \Delta x_{1}=x_{1}^{+}-x_{1}^{-}=\left(1-a_{1}^{2}\right)^{\frac{1}{2}} \ln \left(1-\frac{4 M_{0}^{2}}{4}\right) \\
& \Delta x_{2}=x_{2}{ }^{+}-x_{2}{ }^{-}=-\left(1-u_{2}^{2}\right)^{\frac{1}{2}} \ln \left(1-\frac{4 M_{0}^{2}}{4}\right)
\end{aligned}
$$

wheye is the wound Mandelatam variable.

We now conelder the a-B acottering aroplitude written in the path integral represtatation

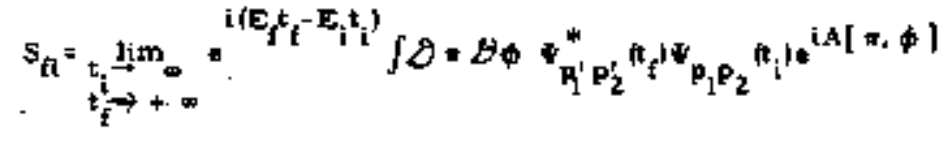

with the ithitial and final wave fusctional, Jefloed by

$$
{ }_{P_{1} P_{2}}[\phi]=\left\langle\phi \mid P_{1}, P_{2}\right\rangle \text {. }
$$

Thle two-particle wave fanctional ia timply obtained from separate -olitan and entinoliton funetionaln. The later are angly dikrived if we lase the fect that for the one soliton aector

$$
\begin{aligned}
& \dot{\phi}(x)=\phi_{\theta}\left(\frac{x-\hat{x}}{\left(1-u^{2}\right)^{\frac{1}{2}}}\right)+\hat{\eta}(x) \\
& \int d x \phi_{\theta}^{\prime} \dot{\eta}=0
\end{aligned}
$$

where the bats denote operators in the sehradinger picture. Now

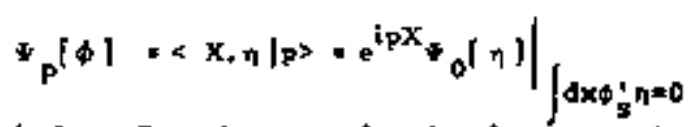

where ${ }_{0}$ alande for a Gaugeian wave functiongl repreaenting the cround state. From this we conclude that

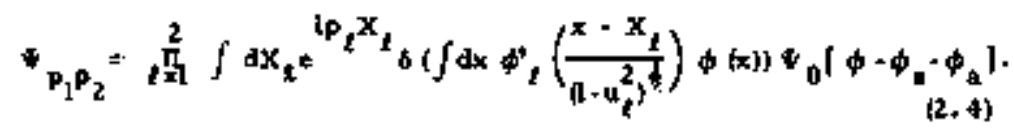

$A$ the next otep we apply the collective coordinate method to separate and integrake out the vartabled correpponding to apace and time tranglalions. The realt reade

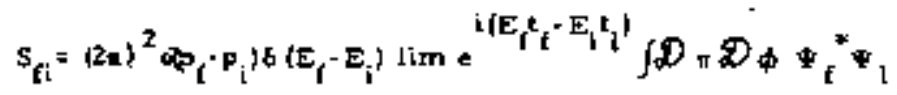

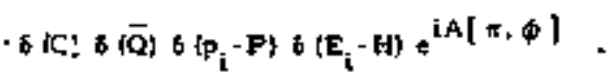

Fore $P$ and $\mathbf{g}$ denote the total momentum and the hamiltonien while $Q$ and $\bar{o}$ repreant erbitrary gauge conditiong. We make the cholce

$$
\begin{aligned}
& Q[\phi]=\int \mathrm{dx} \phi_{s o}\left(\phi-\phi_{s e}\right] \\
& \bar{\phi}[\phi]=\int \mathrm{dx} \phi_{4 \mathrm{a}}\left[\phi-\phi{ }^{\prime}\right)
\end{aligned}
$$


$-10$.

whlch leads to an elegant elimuation of zero frequency modes which are associated with space and time translations. At the initial and final times the conditions $(2.6)$ imply

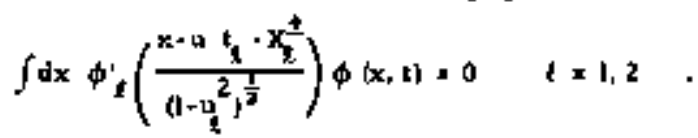

Therefore only the values

$$
\begin{aligned}
& x_{q}=v_{R} t_{t}+x_{t}^{-} \\
& x_{R}^{\prime}=v_{R} t_{t}+x_{q}^{+}
\end{aligned}
$$

contribste to the integrals which appear in the initial and (Inal wave

tunctiona1s.

At thil point we are zeady to do peftufbation about the stationary point $\phi_{\text {aa }}$ by making the whift

$$
\begin{aligned}
& \phi=\phi_{* *}+\pi \\
& \pi=\phi_{*+\infty}+\pi_{\eta}+
\end{aligned}
$$

We will be concerned only oltb the arot quantum correction to the clas. sical angwer and th thig approximaticn the puth ir.tegral expresaion for the ara scaltering phoget shift rode

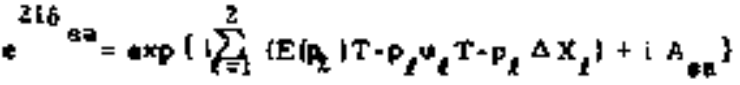

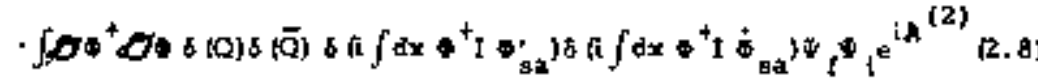
with the notation

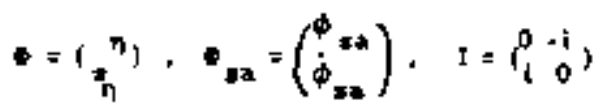

and the quadratic actlon given by

$$
\begin{gathered}
\left.A^{(2)}=\frac{1}{2} \int \partial t d x \phi^{+} H_{2}\right] \Delta \\
H_{2}=i\left(\begin{array}{ll}
\partial / \partial t & -1 \\
-\frac{\partial^{2}}{\partial x^{2}}+v^{(2)}\left(\phi_{a^{2}}\right. & \partial / \partial t
\end{array}\right) .
\end{gathered}
$$

From the expresaion $(2+8)$ we sev that the leading contribusion reade

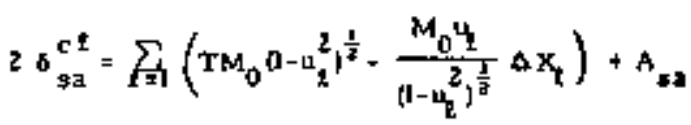

which ts the claastcal phase shiti ${ }^{\{4,5,10\}}$. We point out here that the preclge specification of initial and Einal wave functionals appeared to be necegsary in order to obtan this answer, Otherwise one would haye to supply the firat two terms in (2. lol eacentially by hand.

$$
\text { To complute the firal quantum correction we netd to evaluate }
$$

the Gsugsian functional integral *ith conatraint*. This is done by flnding the norral modes at follows. Firt, we solve for the complete get of solutons to the equation al motion $\mathrm{H}_{2} *=0$, which condist of the dis-

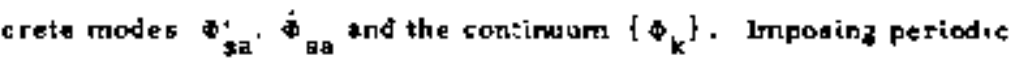
boundary conditions we calculete the alability angles" $\nu_{n}$ and abtain a stt of orthonortal eigeniunctions.

$$
\begin{aligned}
& f_{n}(x, t)=e^{i \frac{v_{n}}{2 T}} \cdot{ }_{k}(x, t) \\
& H_{2} t_{n}=-\frac{v_{n}}{2 T} f_{n}
\end{aligned}
$$

with the inner product defined by

$$
f, g)=\int d x f^{+}(x)[g(x) .
$$

Now we atill have to consider the zero frequency mode which in fact 
have zero noras. However, in order to satisfy the itrat two subsidhary conditions in $[2.8$ ) we need to define a rex basi. by graking linest com.

binatione

$$
\tilde{I}_{n}=\left(\phi_{k}-\alpha_{n} \phi_{* 2}-\beta_{n} \phi_{04}\right) e^{L \frac{\nu_{n} t}{2 T}}
$$

and furthermore the zero irequeney modes give idemically zero.

Next, by txpanding the field

$$
\Phi(x, y)=\sum_{n}\left\{7_{n}(x, t) z_{n}(t)+c+c .\right)
$$

we reduct the action to a ot of dectupled harmonte ostillator*

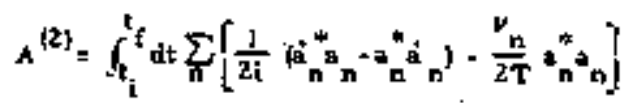

while the [nitiel and find wave functionkls give pras: gely the cround atake of thie onellator. Conenquently the expression for the firot quan. tum correctlon reade

$$
26^{9}=M^{(1)} T \sum_{1}^{2}\left(2-0_{0}^{2}\right]^{\frac{1}{3}}-\sum_{n} \frac{1}{4} v_{n}
$$

where $M^{\text {il }}$ denoted the quabtum correction to the sollton mase. After renormalkation and some calculation we obtato ln the C+M. frame the following answer

$$
8_{0 u}^{q}=-\frac{2}{\pi} \int_{0}^{u} d z \frac{t n z}{1-z^{2}}+\frac{2 u}{\pi} \ln u+\frac{1}{4} \pi .
$$

For oomparison, the elaseicel phase chlft is given by

$$
f^{c t}=\frac{16}{y} \int_{0}^{u} d z \frac{t_{n z}}{1-z^{2}}+\frac{4 H^{2}}{Y}
$$

An interating conjecture concerning the exact solitonanticoliton scattering amplitude has been made bi Faddeev, Korepin and Kulish. Namelyi knowing the classical result (2.16) and also the hound state spectrun this author's conjectured that for spectal jalues of the coupling constant

$$
Y^{\prime}=\frac{8 \mathbf{T}}{\mathrm{H}}, \mathrm{N}=1,2, \cdots
$$

in this s--ory there is no reflection and that

$$
s_{k a}={ }_{n=1}^{N-i}\left(-\frac{\xi+e^{i \frac{I n}{N}}}{1+\xi e^{i \frac{k n}{N}}}\right)
$$

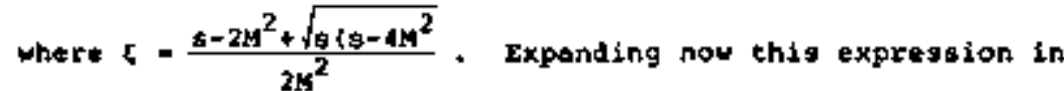
the coupl.ing toristant $y$ one indeed obtains for the first and second kezps precisely $(2.16)$ and $(2.15)$

At it:e end of this section connent it in orater concerning the fact that up to now we were discussing only the trangition port of tbe full s-a amplitude. The guestion is whether the reflection part can be treated in a similat fashion. One fay doubt this since at the elassical level there existg no solution describlog reflection and it is a purely quantum effect llike tunnoll1eg in quantum mecharics). Howtvar, it has betn shown by Korepin :n ref. (12) that by unploying complex time trajectorieg in the path integral it is poscible to give a semiclaseical treatwent of reflection. Namely, if in the usual soliton-antisoliton classica: solution

$$
\left.\phi_{c a}:=, t\right)=\frac{4}{y} \operatorname{tg}^{-1}\left(\frac{\frac{1}{u h} \frac{u t}{\left(1-u^{2}\right) 1 / 2}}{\operatorname{ch} \frac{x}{\left(1-u^{2}\right)^{1 / 2}}}\right)
$$


$-13-$

we chose the followng tine contour

$$
\begin{array}{ll}
\operatorname{Im} t=0 & t<0 \\
\operatorname{Im} t=\frac{\operatorname{a(1-u^{2})1/2}}{0} & t>0
\end{array}
$$

than this solution describes reflection. Taking into account the two possible ways of approuching the turning point $t_{0}=1 \pi\left(1-u^{2}\right) 1 / 2 / 20$ one darives an expression for the reflection part of the a-p actutering anplitude. Interestivgly encugh, for

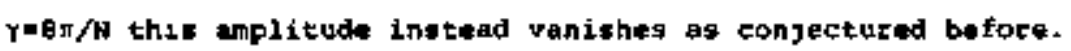

\section{NONCANONICAL COLLECTIVE COORDINATES}

Wo will now dracribe an alternative treatmem of zoro irequency mode ${ }^{13}$ in whleh the symmetry parameters are not promoted to new canonical vartiablea, but are rather treated es ordinary integ tation var. lables In the path Integral. Consequently thio methad is noe canonlcal bat it appeara to be aimpler than the one 1oacribed in eection $t$.

For llustration we congidęr a two-dimenopional acalat field theory

$$
\left.\mathscr{L}(\phi)=\xi(0 \phi)^{2}-v t \phi\right)
$$

posseouing a atakle clasteal solutlon $\phi_{0}(x)$. After the shift $\phi(x, t)=$ $\phi_{0}(*)+\eta(x, t)$ the chatiratic part of the setion read.

$$
\begin{aligned}
& A^{[R)}[\pi]=\int d t d x \frac{b}{a} \eta \hat{H} \pi \\
& M=-\frac{a^{2}}{a t^{3}}+\frac{a^{2}}{\partial x^{2}}=v^{(2)}\left(\phi_{0}(x)+\right.
\end{aligned}
$$

$-14=$

$\hat{M D}\left(x, t ; x^{\prime}, t^{\prime}\right)=16\left(t-t^{+}\right) \delta\left(x-x^{\prime}\right)$

and the corresponding eugenvalue problem in the box

$$
\hat{M} f_{\operatorname{mn} n}\{x, t\}=\lambda_{\operatorname{mn} m n}\{x, t\}
$$

lo solved by

$$
\begin{aligned}
& f_{m n}\left[x_{1} t\right)=\frac{e^{i} t^{t}}{\sqrt{T}} \psi_{n}(x) \\
& \lambda_{m n}=t_{m}^{2}=w_{n}^{2}, \nu_{m}=\frac{21 m}{T} .
\end{aligned}
$$

Here $\left\{\psi_{n}\right\}$ repreatenta somplete ate of eiserifunctions of

$$
\left[\cdot \frac{\partial^{2}}{d x^{2}}+v^{(2)}\left(\phi_{0}\right)\right] \psi_{n}(x)=\alpha_{n}^{2} \psi_{n}(x)
$$

and we a aume that it consiate of the tranblational zezo frequeacy

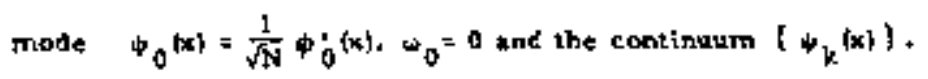

Now the "nalve" expresalon for the propagatar which resde

$$
\sum_{m, n} F_{m n}(x, t) \frac{1}{n_{m n}^{-i E}} f_{m n}^{*}\left(x^{\prime}, t^{\prime}\right)
$$

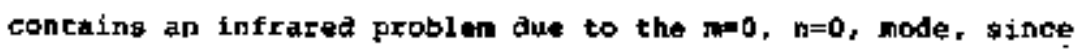
then $\lambda_{00}=0$. Hovever, in the path integral it is possible to preserve the translational symetry and intraduce a oubsidiary condition of the fort

$$
\int d t d x t_{00}(x, t) \pi(x, t)=0
$$

by the argivent aue to Faddeat and Popor which we describe in detail later. Conseguentiy we have the more sensible experession for the propagator

The equation aatlafied by the "nalve't propagatot is then 


$$
\begin{aligned}
D\left(x, t ; x^{\prime}, t^{\prime}\right) & =\sum_{k} \int \frac{d v}{2 \pi} e^{i v\left(t-t^{\prime}\right)} \frac{i}{v^{2}-4(t)^{2}+i t} H_{k}(x) t_{k}^{*}\left(x^{*}\right) \\
& +\sum_{n ; 0}^{+} \frac{i v_{m}\left(t-t^{*}\right)}{T} \cdot \frac{i}{v_{k}} v_{0}(x) b_{0}\left(x^{1}\right)
\end{aligned}
$$

gere the first part represents the contribution of continum modes and it is the usual propagator of the sanonical collective coorainate method denoted by $G\left(x_{r}, ; x^{1}, t^{\prime}\right)$. But, now in addition we have the contribution coning tran the zets mode which cas be eumber up to read

$$
\left.G_{0}(x, t) x^{\prime}, t^{\prime}\right)=i\left[\frac{T}{I 2}-\frac{1}{2}\left|t-t^{\prime}\right|+\frac{1}{2 T^{\prime}} \mid t-t^{\prime} t^{2}\right] \psi_{0}(x) \psi_{0}\left(x^{\prime}\right)
$$

How, we show how the gubsidxary sondition \{3.6\} is introduced.

"Namely, into the path integral expzession ter the one soliton rector transition amplitude

$\left\langle p \cdot \mid e^{-1 t T r} p\right\rangle=\int g_{\phi} \psi_{p}[\phi(T)] \psi_{F}(\phi(0)] e^{i A[*]}$

we ingert the identity

$$
\begin{aligned}
& \int d a d\left(\int t d x f(x, t) \phi(x-a, t)\right) J=1 \\
& J=\int d t d x f(x, t) \frac{a}{\partial a}+(x-a, t)
\end{aligned}
$$

Hext, changing variablea $\phi(x, t)+\phi(x+d, t)$ what lopleas

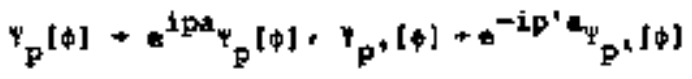

and partoreing the integration over $a$ we obtain

$$
\begin{aligned}
& 4 F^{\prime}\left|e^{-2 H T}\right| p>-(2 \pi) 6\left(p^{*}-p\right) F(p) \\
& F(p)=\int \theta+\psi_{p}^{*} \psi_{p} \phi(d t d x \quad f(x, t) \phi(x, t)) J t^{1 A[t]}
\end{aligned}
$$

Here $f(x, t)$ is arbitrary and abstryt that the subsidiary condition in this path integral is not canonical. Now for the xero monuntum cabe one oimply chooses $f(x, t)=t_{\infty}(x, t)$. In general for arbitrary monepita ve have to use the time dependent solution instese of the stetic one. Furthermore it is possible to introduce even a more general trantation invariance fixing term tran the f-function in (3.11). By the wall-known argument one derives for exanple

$F(0)=\int \theta_{n} J \exp \left(2 A\left[\theta_{0}+n\right)+\frac{i}{2 \alpha},\left(\int a t a x \theta_{0}(x) \eta(x, t)\right)^{2}\right]$

and then the zero mode part of the propagator reads

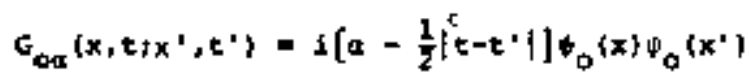

Here $a$ is arbitrary and the depandence on this paraneter cancels out in the calculation ${ }^{(14)}$ The Feynmon rules are completed with the vertices conjing from the higher than quadratic part of the action and also the Jacobian.

Tine advantage of the method deacribed above is in its simplisity. 
Firgt of all, it appears that the transformation which was performed to introduce the collectivg coordinte dots not requite any special treatment in contrast to the case of canonical transformations discusbed in section I. This virtue ia especially ugeful in developing for example the perturbation expansion for soliton scattering, Applying the mothod of this section to that case one easily derives a eimple set of Feynnen rules fnow the propogator contains the contribution of two zeto modus). which can then be usect to perfor even higher lopp calculations. (15)

Furthermore, being noncaronical this method is also appropriate for tresting the rero-irequency modes which apper in perturbetion expanston about instanton solutions. for exapple, let us consider the su(2) lnveriant Eucliastin Yong-hille tield theory

$$
\begin{aligned}
& \mathscr{L}=-\frac{1}{4} F_{\mu v}^{\mathrm{a}} F^{\mathrm{a} \mu v} \text {. }
\end{aligned}
$$

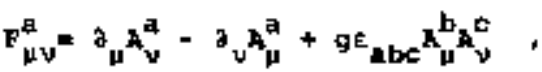

posgessing an exect claseical solution

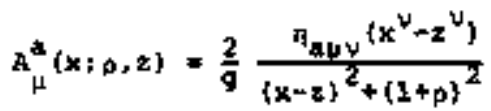

fourd by Belavin et al. $[17)$ Here $x^{v}$ and $p$ are arbitracy constants associated wh transiation and scale invariance. The corteoponding zetro-freģuepcy eigenfunctiops pow read

$$
\begin{aligned}
& \phi_{\mu}^{a}(x)=\left.\frac{\partial}{\partial \rho} A_{\mu}^{a}(x ; \rho, z) d 1\right|_{p=0,2=0} \\
& \phi_{\nu}^{a}(x ; \nu)=\left.\frac{\partial}{\partial x_{v}} A_{\nu}^{a}(x ; \theta+z) \mathrm{el}\right|_{g=0,2=0}
\end{aligned}
$$

The zero-frequency modes aspociated with the su(2) internal symutery read

$$
\psi_{\mu}^{a}(x ; a)=\left.\frac{\partial A_{\nu}^{a}\{x ; h\} a 1}{\partial T_{\alpha}}\right|_{\Lambda=0}
$$

where ve denoted

$$
\begin{aligned}
& A_{\mu}(x ; A)=U^{-1}(A) A_{\mu}(x) U\{A), \quad U(A)=\exp \left(i g \Lambda^{a}{ }^{\alpha} / 2\right), \\
& A_{\mu}(x)=A_{\mu}^{a} 1^{a} / 2 .
\end{aligned}
$$

The gauge is tpecifled by $c^{*}(x)=a^{\mu} A_{\mu}^{*}(x)$ and the vacuum to vacular anplitude which we consider then has the following path integral form:

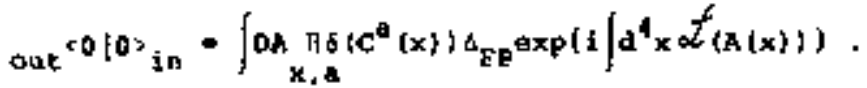

To proceted we ned to introduce the notion of invariant sti2\} group integration

$$
\int d u(A)-\int\left(v(g A) \prod_{a=1}^{3}\left(g d A_{a}\right) .\right.
$$

and the following condensed notation for the zero-frequency mothes

$$
\begin{aligned}
& \varphi_{\mu}^{a}(x)=f_{u}^{a}\{x ; 1\} . \\
& \psi_{\mu}^{a}(x ; v)=f^{a}\{x ; v+1) \\
& \psi_{\mu}^{a}(x ; a)=f^{a}(x ; a+5) \quad a=1,2,3,4 .
\end{aligned}
$$


To eliminate this modes we insert the identity

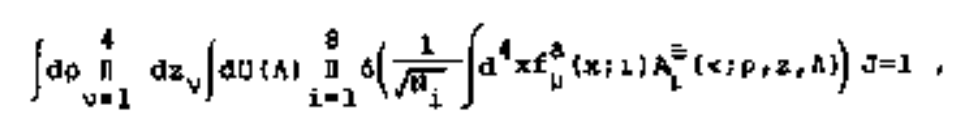

inte the fath integral. Now changing the fizld integration variables $A_{\mu}^{a}(x ; 0, z, h)+A_{\mu}^{B}(x)$ we obtsin

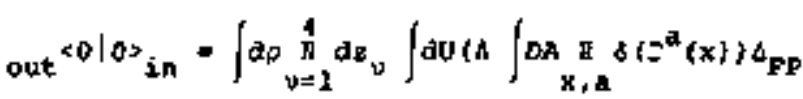

$$
\begin{aligned}
& \prod_{i=1}^{g} \delta\left(\frac{1}{\sqrt{A_{i}}} \int a^{4} x t^{a}\{x ; i\} A^{\Delta}(x)\right) \exp \left[1 \int \exists^{4} x Z^{2}\right\}
\end{aligned}
$$

Here the Jacobian $J$ to to be evaluated fron :3.22) using infinites: imal symetry trangformations and is given b:

$$
\begin{aligned}
& S=\frac{1}{g^{3}} \operatorname{det} N_{i j} \\
& M_{i j}=\left.\frac{1}{\sqrt{F_{1}}} \int d^{4} x f_{\mu}^{a}(x \neq i) \frac{\partial \lambda^{a}(x f a)}{\frac{\partial a}{j}}\right|_{a=0} ^{-}
\end{aligned}
$$

where $\bar{a} \equiv\left(0, z^{\nu}, n_{a}\right\}$. Tor explicit goe-loop calculations the revder is referred to ces. (16). Te also mention that it is possible to give a canonical deccription of vacuup turalling ilb) in theorite with instartons by anploying the canonical zellective coordinate anthod digcussed in sect.I.

\section{REPEFEWCES}

(1) E. Dashen, B. Hasslacher antf A. Weveu, Phys. Rẹv. D 10, 4114 [1974); 10, 4130 (1974).

(2) J. L. Gọryais and B. Sukitu, Phys. Ftv. D I1, 2943 12975) J. L. Gervaid, A, Jevicki and B. Sakita, Phyo. Rev. D $\underline{12}$, $103 B$ (1975)

(3) For an entirely different approach seef J. Goldstone and R. Jackiw, Phys. Rev. D 11. 1486 (1975).

(4) C. Callan and D. Gross, Mucl, Phys, B $\underline{93}, 29$ \{1975\}.

(S) L. D. Fadđeev, V. E. Kơrepin and P. P. Kulish, JETP Lett. 21, 260 (1975).

(6) J. L, Gervais, A. Jevieki and a. Sakita, Phys, Reparts 23, 237 (2976); tee also A. dogoya and $\mathrm{R}$. Kikkawa Nuc1. Phys. B 101, 271 (1976).

(5) J+ $\mathrm{L}_{+}$Gerveis and A, Jevicks, Nuc], Phys. B 110, 93 (1976) -

(B) E. Tomboulis, Phys. Rev. D 12, 1678 (1975), B. Christ and T. D. Lee, Phys, Rev, O 12, 1606 (1975).

19) I. L. Gervais and h. Jevicki, Mucl. Phys.8110, 113 (1976); for the afscussion of A-soliton scattering see $h$. Jaeckel. Ecole Norwal preprint (1976).

(10) R, Jackiv anat G. Foo, Phys, Rev, D 12, 1643 (1975).

(11) R. Dashen, B. Hasalacher and A. Neveu, Phys, Rev. D 11 . $3424(1975)$.

(12) v. C. Korepin, JETP Lott, 23, 224 (1976); for the complex time" method see D. Mclaughlin. J. Math. Phys. 포, 1099 [1972). 
(13) A. Jevicki, Nuc1. Phys, B, 117, 365 (1976).

(14) L, b. Faddeev and v. E. Korepir. Phys. Latt. 63B, 135 $\{1976\}$, similar propagatora appear also in tho elassical perturbation expangion for solitons developed by J. Ketener and D. Meisughlin tpreprint 19761.

(15) The only bigher loop caleulation performed so for ts the two-loop correction to aoliton mala in the sine-Gordon

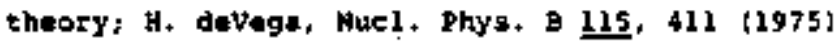

[15) G. 't Hooft. Phys. Rov. D 14, 3432 (1976), A. Polyakov Hordita preprint (1976); E. Brexin, J. C. Le Guillou and J, zinn-Justin, Saclay preprint (1976),

(17) A. A. Belavin, A. M. Polyakov, A. S. Schwartz and Yu. 5. Tyupkin. Phys, Lett. 59B, 15 (1975).

(19) J. L, Gervais and B. Saxita, CCWY preprint (1976). 